\title{
Valorisation of vernacular farm buildings for the sustainable development of rural tourism in mountain areas of the Adriatic-Ionian macro-region
}

\author{
Dina Statuto, Pietro Picuno \\ School of Agriculture, Forestry, Food and Environmental Sciences, University of Basilicata, Potenza, Italy
}

\begin{abstract}
Rural buildings play a central role on the environmental characteristics of the extra-urban land. They accompanied in the centuries the development of agricultural activities by humans, who was so able to breed cattle, to grow and yield crops, and to store, transform and process agricultural products in a functional and efficient way, working into intensive conditions, so being unaffected by the external climate. On the other hand, constructions built by the farmer-man marked the territory, influencing and steering the spontaneous development of nature, while leading to production that enabled humanity to get food. Vernacular farm buildings, often used as seasonal settlements, are in some cases organised in areas of mountain pasture for summer cattle grazing. Even if in most case they were abandoned during recent years since people living there moved to more comfortable residences within urban settlements - their contemporary potential for preserving traditional cattle-raising procedures and dairy products, rich cultural-historical heritage and perspectives of organised tourism activities, appears a very intriguing task to be approached. Rural tourism - including agro-, eco- and cultural tourism - offers indeed new opportunities for enjoying the extra-urban land in close contact with naturally untouched landscapes. It enables to appreciate some traditional aspects that the new industrialised modern society may have forgotten. The opportunities offered by rural tourism could help in the development of environmentally friendly tourism, which is growing three times faster than those choosing mainstream trips. With the aim to valorise the vernacular rural buildings in some mountain areas of the Adriatic-Ionian macro-region, in the present paper a first approach was proposed,
\end{abstract}

Correspondence: Dina Statuto, School of Agriculture, Forestry, Food and Environmental Sciences (SAFE), University of Basilicata, viale Ateneo Lucano 10, 85100 Potenza, Italy.

E-mail: dina.statuto@unibas.it

Key words: Vernacular farm buildings; mountain areas; rural tourism; geographical information system; Adriatic-Ionian macro-region.

Received for publication: 30 November 2016.

Accepted for publication: 26 April 2017.

CC Copyright D. Statuto and P. Picuno, 2017

Licensee PAGEPress, Italy

Journal of Agricultural Engineering 2017; XLVIII(s1):643

doi:10.4081/jae.2017.643

This article is distributed under the terms of the Creative Commons Attribution Noncommercial License (by-nc 4.0) which permits any noncommercial use, distribution, and reproduction in any medium, provided the original author(s) and source are credited. through the implementation of a geographical information system aimed to survey the current situation into two different mountain areas within this macro-region, located in Southern Italy and Montenegro. This first step could pave the way for future possible planning the restoration of these buildings, within the general framework of a concerted approach aimed to their safeguard and the general sustainability of their landscape inclusion, fighting the progressive abandonment of rural land. The exploitation of their unexpressed potential in the sector of tourism usage, together with cultural and historical heritage, rich tradition and old infrastructure, would therefore reveal an interesting profitable way for their valorisation.

\section{Introduction}

The recent growing research of new ways for widening sustainable tourism opportunities leaded, in many European countries, to the enhancement of some farmyards, together with the working activities usually conducted there. Vernacular farm buildings, synthesising in their architectural expression the culture, traditions and way of life of generations of rural populations, were realised in many areas all over Europe, mostly in the Mediterranean area, due to its traditional agricultural vocation, in which farm buildings were conceived in order to fulfill their primary role to support the food production. As an important element in the cultural heritage of a people, traditional rural constructions need to be conserved over time. Graphic and metric documentation methods play a key role in the preservation of cultural heritage (Arias et al., 2006). These constructions constitute a widespread heritage of irreplaceable architectural value, deserving the highest consideration during the process of landscape planning (García and Ayuga, 2007; Picuno, 2012; Statuto et al., 2016). A vernacular farm building is indeed a living witness of how humans have populated, in harmony with the natural elements, the rural land, joining the agricultural production needed for human nutrition with the control and care of extra-urban land (Dal Sasso and Caliandro, 2010; Picuno, 2016). The interventions made by humans often strongly influenced the agricultural environment and the visual perception of its landscape (Hernández et al., 2004; Statuto et al., 2013a, 2014b; Tortora et al., 2015). Agricultural and rural activities now represent a smaller percentage of the gross domestic product than in years past. One of the immediate consequences of this decline has been the large number of redundant buildings in the countryside surrounding rural towns. Little money is made available for the conservation of these buildings, and their progressive deterioration eventually leads to their complete ruin (García and Ayuga, 2007).

Rural tourism offers new ways for enjoying the agricultural land in close contact with naturally untouched landscapes, often coupled with the unique opportunity to personally look at the 
preparation of traditional genuine food products, with the possibility to taste and buy them. In this way, rural tourism enables to appreciate some traditional aspects that the new industrialised modern society may have forgotten. For a sound valorisation of rural tourism, a suitable restoration and functional requalification of the farm building plays a central role (Statuto et al., 2014a; Picuno et al., 2015).

With the aim to plan a common approach about new innovative ways for valorising rural tourism, mainly in mountain areas, in the present paper a first analysis focused on the possibilities of exploiting agricultural activities and restoring vernacular farm buildings for rural tourism was conducted. The analysis refers to some mountain areas located into two different countries of the AdriaticIonian macro-region, i.e.: South Italy and Montenegro. One of the first definitions of rural tourism was proposed by the European Commission in 1986: Rural tourism is a broad concept that includes not only farm tourism or agritourism -accommodation provided by farmers - but all tourist activities in rural areas (European Commission, 1986). Simonicca (1997) interpreted rural tourism as an alternative type of tourism with sustainable objectives (Simonicca, 1997).

This new way for offering tourism in a sustainable way is in close agreement with the new EU Strategy for the Adriatic and Ionian Region (EUSAIR), a macro-regional strategy adopted by the European Commission and endorsed by the European Council in 2014. One of the main four pillars of this new EU macro-regional strategy is in fact concentrated on sustainable tourism (http://www.adriatic-ionian.eu/).

Since this study is focused on the environment and landscape assets - with a particular interest on the natural, archaeological, historical and artistic components - present in the two study areas, with a special focus on the rural buildings and historic farms, a geographical information system (GIS) was employed to support the analysis in a planned and efficient approach. A GIS can be helpful in different ways, because it can be considered as a valuable tool for managing, analysing, and displaying large volumes of diverse data to many different levels of planning activities (Statuto et al., 2013b). The results of this survey enable the drafting of an innovative common protocol for planning suitable technical and economical interventions aimed to the revitalisation of mountain rural areas, through the organisation of a network focused on the valorisation of common agricultural activities and production of local traditional foods. These results are the basis for an exploitation of rural tourism activities, geared by the restoration of vernacular farm buildings according with particular common specs, able to recover them in such a way to balance at the same time their traditional vocation and the environmental sustainability of the landscape they are incorporated into (Statuto et al., 2015). The reuse of abandoned vernacular buildings usually results in economic, sociocultural and landscape benefits for promoters and the local society as a whole. Saving in energy and building materials, creation of jobs and new economic activities, promotion of the cultural tourism, preservation of a valuable documental source about countryside culture, recovery of native construction techniques, community encouragement, and a more pleasant appearance of the villages are some of the most significant positive consequences of reusing redundant buildings (Fuentes, 2010). Cultural and rural tourism has been used, for instance, to promote the development of the region of Marmilla (Sardinia region, Italy) by promoting its strengths and making improvements that, until now, have been linked to less traditional tourist flows (Garau, 2015).

\section{Materials and methods}

With continuing innovations, the information communication technologies (ICT), social networks, and mobile applications can facilitate the integration of tourism products in different moments of the consumption process. They have changed how tourists search for information on different places and evaluate their alternatives (Garau, 2015). Traditional farm buildings were originally erected to play a role linked to agricultural works. Therefore, a significant material heritage (machinery, tools and other specialised objects) remains inside the buildings; considering the particular historical aspect of these objects it could be possible to create opportunity for the renovation of vernacular farm buildings, using them for touristic purposes.

\section{Study areas}

The typological characteristic, building condition and status of use of vernacular farm buildings were identified with the aim to detect and compare their architectural aspects with reference to two mountain areas located in different Countries within the Adriatic-Ionian macro-region, i.e. Basilicata region (Southern Italy) and Montenegro (Figure 1). In these two areas, the analysis was conducted in order to identify the most popular features of these buildings, so as to assess the possibilities to restore them, converting them to an agro-tourism use. Information related to buildings have been organised in order to determine: identification, location, topography, landscape features, type of settlement, distance to populated centres, available services, general building characteristics, number of floors, structural system, roofs and facades characteristics, architectural details and particular study of building features according to the specific use; material heritage linked to the building (Fuentes, 2010).

\section{Italy - Basilicata}

The Basilicata region covers a total surface of almost 10,000 $\mathrm{km}^{2}, 90 \%$ of the whole territory being mountain. It has a population of about 600,000 units, distributed into the two provinces of Matera and Potenza. The Basilicata region embodies much of the variability of landscapes found in southern Italy. In addition to the geological variability, the territory of the region has a remarkable morphological variability, with the presence of surfaces dating to very different ages and a great variability of soils that were formed within these environments (Tortora et al., 2015).

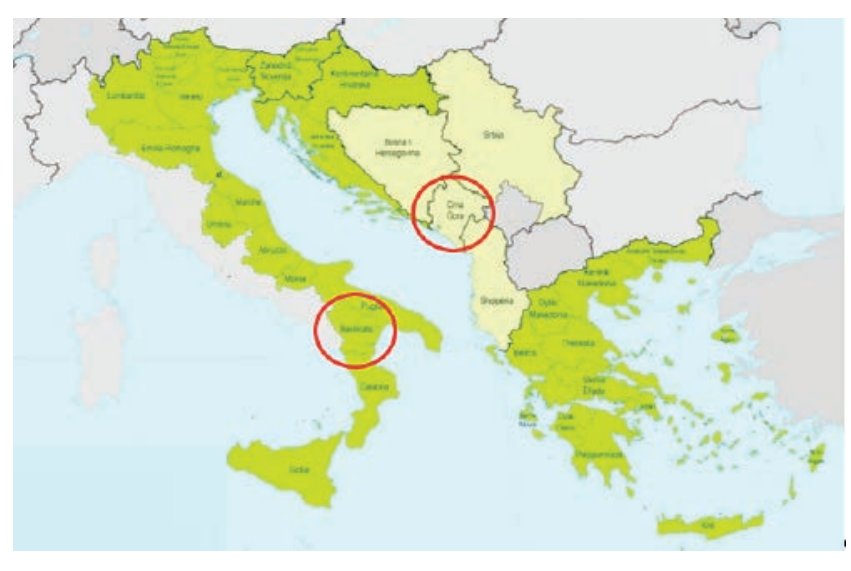

Figure 1. Adriatic-Ionian macro-region and the two study areas, i.e. Basilicata Region and Montenegro. 


\section{Montenegro}

Montenegro is situated in South-east Europe, on the Adriatic Sea. It covers a total surface of almost $14,000 \mathrm{~km}^{2}$. With its population of about 660,000 inhabitants, Montenegro represents one of the smallest European countries. More than $90 \%$ of its territory is rural in character and great diversity of natural and built resources and attractions in rural areas offer wide possibilities for a sustainable valorisation, especially through rural tourism and other complementary activities. Montenegro has large hilly and mountainous areas with distinctive relief and only small areas of lowland. The country is intersected by deep and narrow river valleys and mountain chains. Such geography and climate conditions have created high diversity in landscape, in biodiversity, in agriculture, and in areas of high natural value farmlands. These areas preserves very rich and multi-layered historical and cultural heritage. It is visible in housing architecture, customs and customary law's code, traditional poetry, anecdotes, buildings' internal organization and many other aspects.

\section{Data analysis}

The spatial distribution of the vernacular farm building, socalled Masserie in the whole territory of the Basilicata Region, as well as of traditional Katuns in some areas of Montenegro, was analysed, and the relevant geo-database was implemented into a geographical information system (Q-GIS), which enabled a spatial data analysis.

\section{Italy - Basilicata}

The analysis performed in Basilicata region has confirmed the main role played by altimetry in characterising different architectural types: mountain and high-hilly areas are in fact recurring types of lodging characterised by a simple construction, realised with locally available building materials, i.e. stone, wood, etc. (Figure 2). The altimetry play an important role in characterising different architectural types: mountainous and high hilly areas are in fact recurring types of lodging characterised by a simple construction, often on one floor. In areas at lower altitudes, the rural housing was expanding in size, in many cases including, in addition to the main house of the owner, also residences of the settlers and the structures used for the livestock production activity or processing of the agricultural products (Figure 3). Unfortunately, in the recent years, the most part of the vernacular farm buildings whether on hill or mountain areas were abandoned, as it was evidenced through a specific

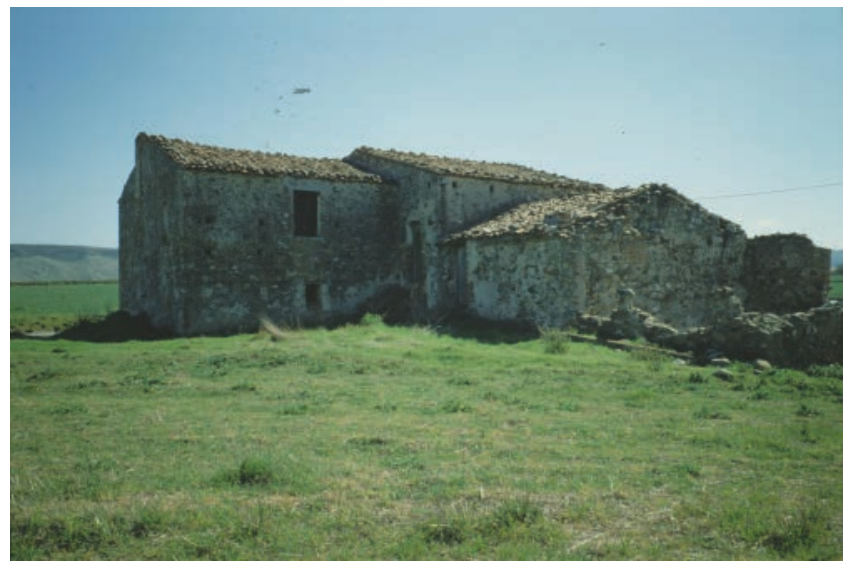

Figure 2. Vernacular farm buildings in a mountain area in the province of Potenza. targeted analysis conducted by Manera et al. (1990). The core methodological procedure used in this study was based on a geographically spatial method, combined with some direct investigations that, identified as a field method, included a direct exploration followed by a relevant detailed survey.

\section{Montenegro}

The analysis on rural farm buildings in Montenegro was focused on the Montenegrin Katuns that constitute a special example of rural buildings; used as seasonal settlements - where the agricultural households stay with livestock during the summer season, most frequently for 4 to 5 months (from the end of May until October) - they are organised in areas of mountain pastures for summer cattle grazing. The main purpose is to use mountain pastures for rearing farm animals and producing traditional milk and meat products, which is the main source of income for these households (www.katun.me/index.php).

In terms of buildings, the Katuns settlements include different types of wooden or stone structures cottages for household members, mainly without electricity and water, where traditional production of cheese and other dairy products is still going on. The building is realised with a thick wall in dry stone (rectangular or circular base), with small doors and some niches and it is covered with a particular wood roof (Kapetanović et al., 2016). Even if in most case they were abandoned during recent years - since people living there moved to more confortable residences within urban settlements their contemporary potential for preserving traditional cattle-raising procedures and dairy products, rich cultural-historical heritage and perspectives of organised tourism activities, appears a very intriguing task to be approached (Lakovic et al., 2016).

During a recent research, Koprivica et al. (2016) visited, photographed and mapped all Katuns, sites and objects of cultural-historical importance in some study areas. There, the data on their condition, population number, purpose and current state of existing objects were taken. Every Katuns was geo-tagged and placed in a Q-GIS database, so as to pave the way to preserve and revitalise them, via implementing new activities to enable them to become distinctive and attractive tourism destinations.

For the purpose of the present article, the Mountains of Kuči area was selected thanks to its social aspects, richness in cultural heritage, tourism attractions, architecture, as well the presence of typical Katuns (Figures 4 and 5) and certain positive trends in the development of agriculture (sheep and cattle rearing and produc-

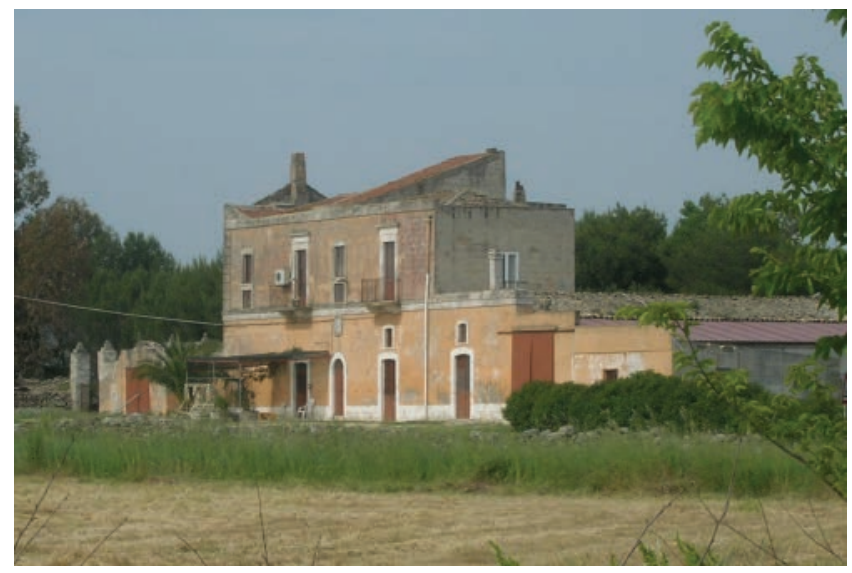

Figure 3. A unitary hilly form of Masseria in the province of Matera. 
tion of specific dairy products, as well as new sectors of agricultural production like growing of potatoes, buckwheat, cereals, etc.). According to the existing data, this area is also rich in diversity of plant and fungal species, which could be valuable for commercial use and benefits for rural populations. A best management practice is then necessary to be established, in order to provide balance between commercial usage and needs for an environmental protection and sustainable management.

Due to landscape characteristics, this area is becoming very popular among the backpackers of all kinds, being situated in the nearest vicinity of the Podgorica and its transport, infrastructure and logistic facilities. The tourism development here is aimed on following two directions - further promotion of the existing activities from the domain of active - adventure tourism, as well as introducing the agro-tourism as a new category. To implement the strategy and promote the historical and the natural heritage for touristic purpose, the following step in the GIS analysis were considered: i) identification of the distribution of rural building; ii) selection of the most attractive points of interest; iii) insertion of the points of interest in the GIS and creation of a geo-database; iv) creation of exemplificative maps useful to describe the territory.

\section{Results and discussion}

The distribution of Masserie within the territory of the whole Basilicata Region (Figure 6) was determined starting from a survey conducted in 2014 (Grano, 2014), while the results about the Kuči area in Montenegro (Figure 7) were presented in a previous article (Lakovic et al., 2016). These data were included into the GIS, together with other parameters, i.e., roads, administrative boundaries, vegetation and geomorphology.

The variables were combined into the GIS model to produce maps portraying the location of rural buildings that can be used for touristic purposes. The maps generated with this GIS-based model can be used by farmers who are considering the option to start a new agro-tourism activity in their farm, or by state-wide economic Entities, tourism development agencies, etc. The resulting geodatabase contains for each building relevant information about the location, the relation with infrastructures, land cover, morphology, vegetation, etc.

The results of the GIS analysis are important to define some possible touristic or cultural itinerary - an achievable promotion strategy - for the enhancement of historical heritage aimed at encouraging the development and creation of touristic itineraries that can form the basis for proper planning and territorial management (Figure 8).

The GIS database that was specially designed could be considered as a method/instrument for the representation of the territory and the identification of particular point of interest, able to promote the communication and to contribute to tourism development. This instrument allows appreciating from a cartographic point of view the distribution of historical and natural heritage, rural buildings and farms, etc.

The dominant vegetation and the particular type plays an active role for the livestock activities and for the dairy production, since the characteristics of vegetation can influence indeed the smell of dairy products, through the feeding chain of the animal that are bred there (Manera et al., 2001). The limited distribution of important road network, the presence of natural vegetation, the mountain aspect and the absence of urbanised area are important characteristics that constitute an unexpressed potential in the sector

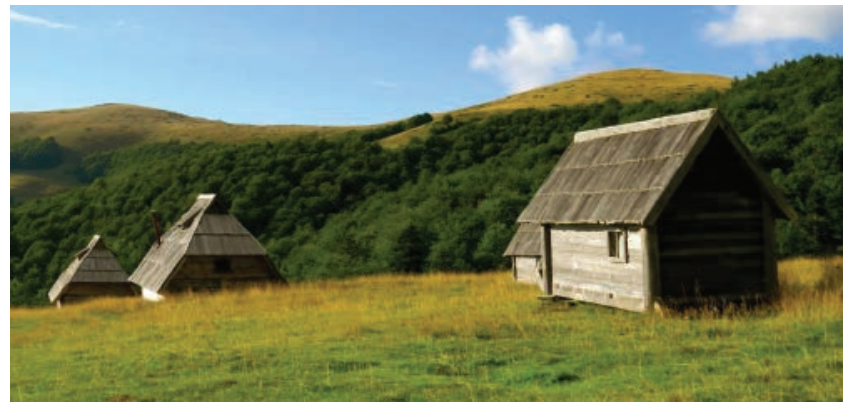

Figure 4. Katuns in Montenegro.

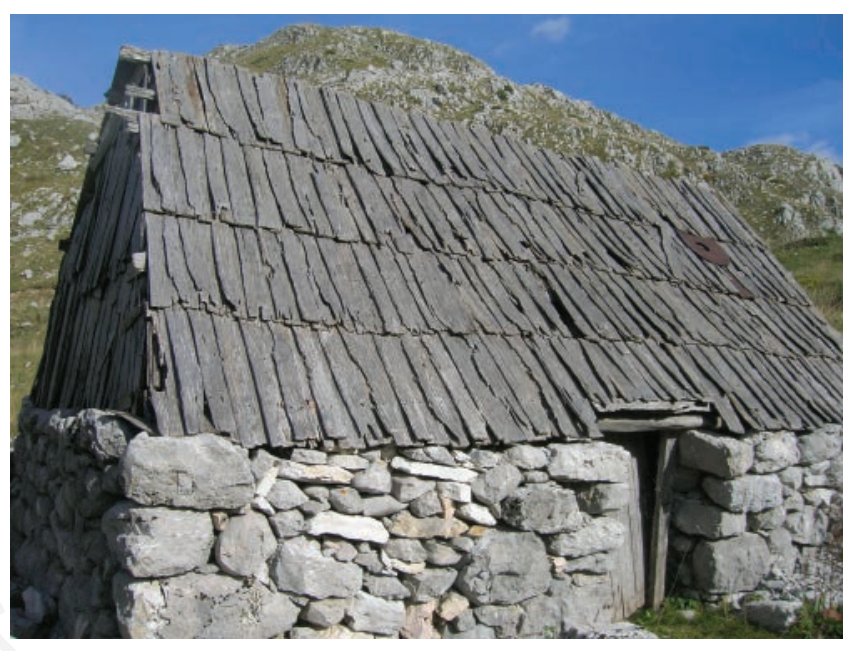

Figure 5. A typical Montenegrin katun in the Kuči area.

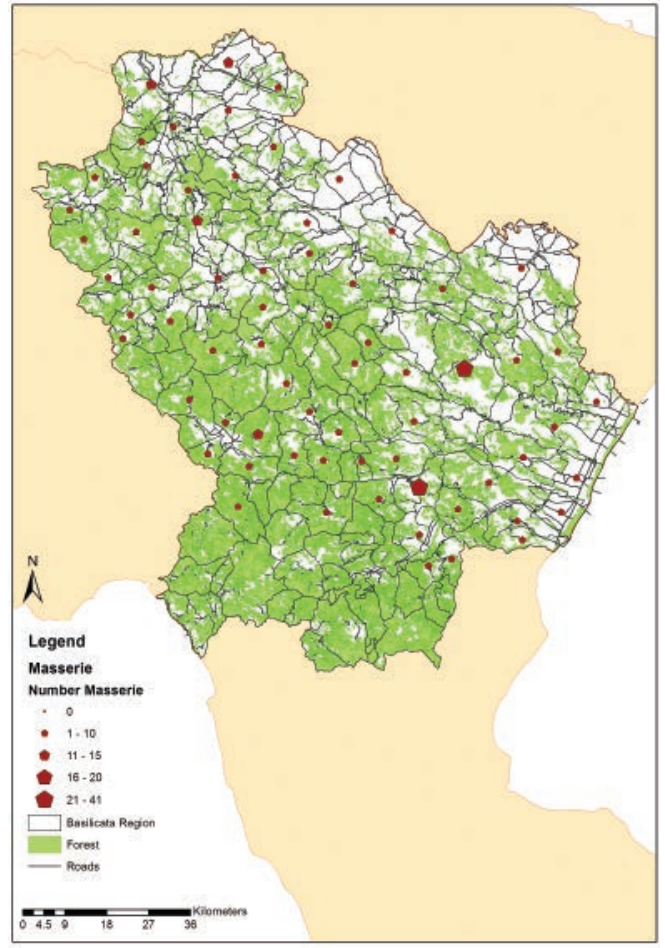

Figure 6. Spatial distribution of Masserie in the Basilicata region. 
of tourism usage. Tourists that visit this mountain area in Basilicata region and in Montenegrin mountains of Kuči have the opportunity to enjoy the natural landscape, to visit the farms, taste local products, and take part into the agricultural practices. In this natural landscape, there is also the chance to taste some of the forgotten national specialties.

\section{Conclusions}

The geo-database presented, that is the result of the territorial analysis with the support of a GIS, represents an instrument for safeguarding the territory and promotes rural buildings for touristic purposes. Livestock production, particularly rearing of ruminants, is the only rational way for valorising less favoured areas, and a suitable tool of preserving the cultural landscape of historical and typical rural buildings. In addition to its economic and nature conservation role, agriculture is also important for its social component. Integration of nature conservation measures into development of the sustainable tourism is an important contributor to the concept of the ecological state. Since sustainable tourism is one of the pillars of the EU Strategy for the Adriatic and Ionian Region (EUSAIR), a plan for the systematic identification of Masserie and Katun through the implementation of ICT tools may reveal a fruitful way for implementing suitable actions aimed to the enhancement of rural building heritage; in this way, it is possible to contribute to the protection of natural resources, stimulating at the same time the local economies.

Historical rural buildings, thanks to the value of their authenticity and original character, may contribute to promote the territory considering the historical, cultural and environmental heritage of the Basilicata region and Montenegro mountains. Thanks to the implementation of a geo-database, it is possible to create signifi-

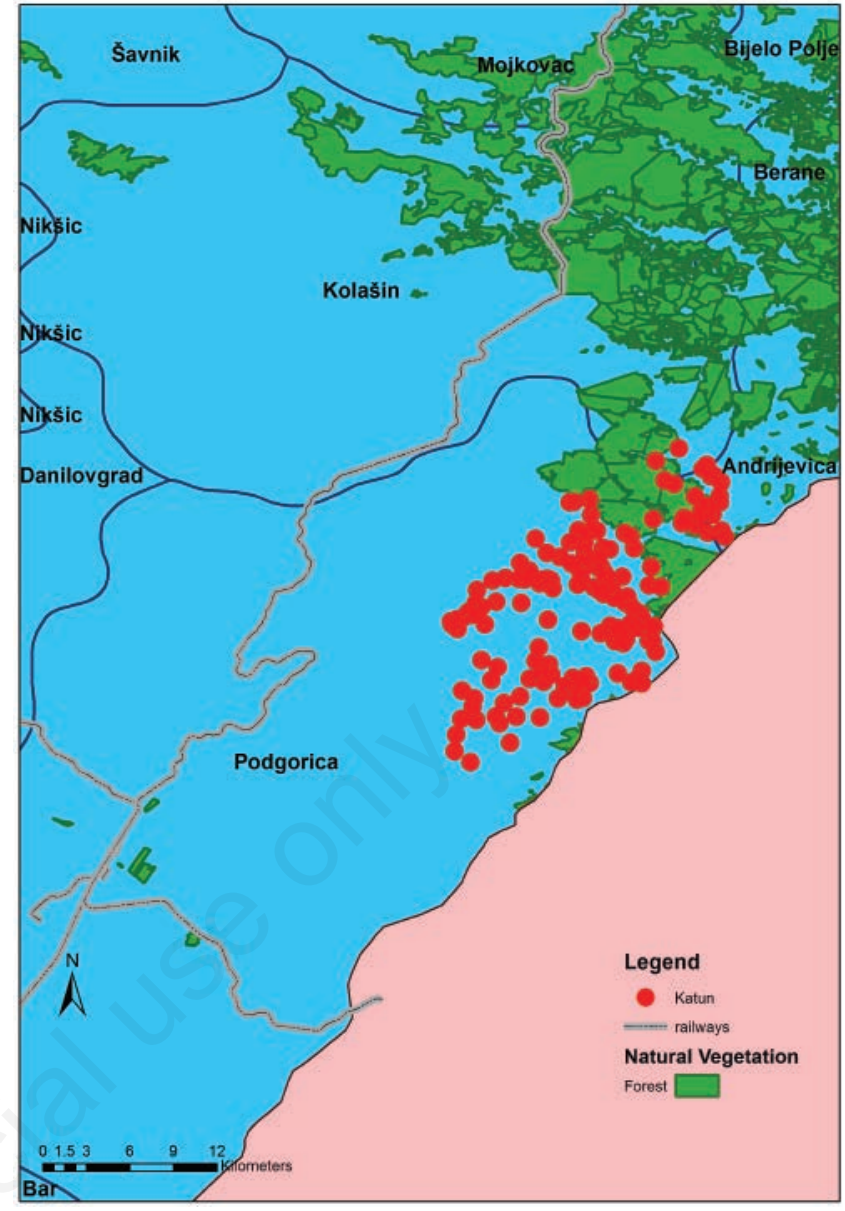

Figure 7. Spatial distribution of Montenegrin katun in the Kuči area.

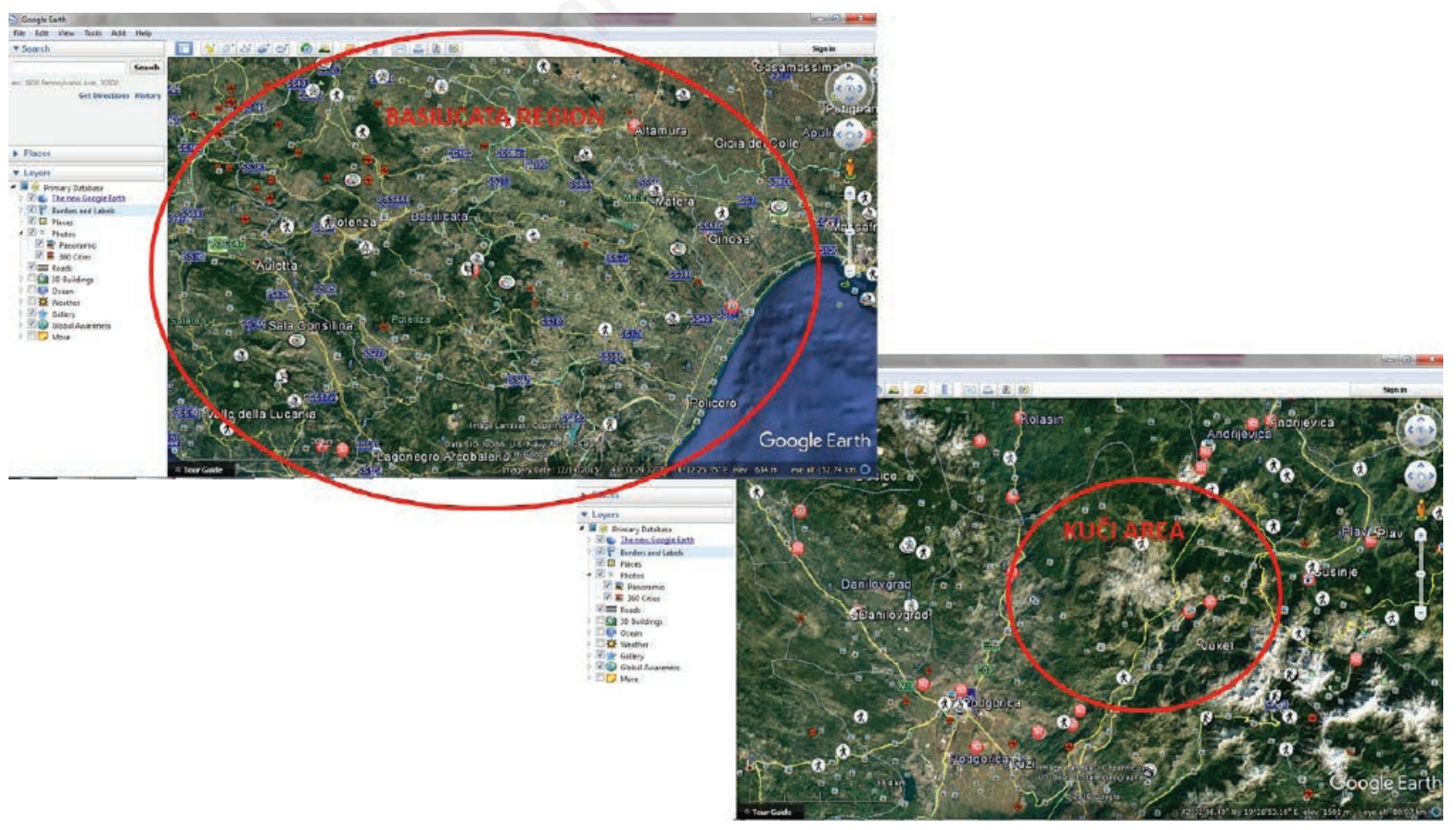

Figure 8. Spatial distribution, touristic itinerary and point of interest in the study area. 
cant opportunities to improve the quality of touristic services, as well as promoting the territory through the valorisation of its main typical features and local agro-food productions.

\section{References}

Arias P., Ordóñez C., Lorenzo H., Herraez J. 2006. Methods for documenting historical agro-industrial buildings: a comparative study and a simple photogrammetric method. J. Cult. Heritage 7:350-54.

Dal Sasso P., Caliandro L.P. 2010. The role of historical agroindustrial buildings in the study of rural territory. Landscape Urban Plan 96:146-62.

European Commission. 1986. Community action in the field of tourism. Commission communication to the Council. Bulletin of the European Communities, Supplement 4/86, p. 10. Available from: http://aei.pitt.edu/5410/ Accessed: 21 February 2015.

Fuentes J.M. 2010. Methodological bases for documenting and reusing vernacular farm architecture. J Cult. Heritage 11:119-29.

Garau C. 2015. Perspectives on cultural and sustainable rural tourism in a smart region: the case study of Marmilla in Sardinia (Italy). Sustainability 7:6412-34.

García A.I., Ayuga F. 2007. Reuse of abandoned buildings and the rural landscape: the situation in Spain. Trans. ASABE. 50:1383-94.

Grano M.C. 2014. Paesaggio, strutture rurali e architettura popolare nelle province di Potenza e Matera. In: G. Gabrielli, M. Lazzari, C. Alfieri Sabia, S. Del Lungo (Eds.), Cultural landscapes: metodi, strumenti e analisi del paesaggio fra archeologia, geologia e storia in contesti di studio del Lazio e della Basilicata (Italia). BAR International Series 2629. Archaeopress, Oxford, UK, pp 131-148.

Hernández J., García L., Ayuga F. 2004. Integration methodologies for visual impact assessment of rural buildings by geographic information systems. Biosyst. Eng. 88:255-63.

Kapetanović A., Laković I., Koprivica T., Olga Pelcer-Vujačić, 2016. Cottages in Katuns cultural landscape - architectural features of cottages (Gladas) in Kučka Mountain. Proceeding of International Conference: sustainable development of mountain areas - Experiences, challenges and perspectives, September 14-16, Zabljak, Montenegro, available from: http://www.katun.me/administracija/kcfinder/upload/files/Boo $\mathrm{k} \% 20$ of $\% 20$ Abstracts\%20FIN\%282\%29.pdf

Koprivica T., Kapetanovic A, Lakovic I. 2016. Mountain cultural heritage in Montenegro: a case study of katuns at the Kuči Mountain and Durmitor area. Proceedings of the 1st International Conference on Research for Sustainable Development in Mountain Regions - Mountains 2016, 5-7 October, Bragança, Portugal, Abstract n. S04O07.

Lakovic I., Pekovic S., Statuto D., Picuno P. 2016. The Katuns Rural buildings as a perspective of seasonal mountain settlement in Montenegro. pp 557-566 in Proceedings of the 44 International Symposium on Agricultural Engineering "Actual Tasks on Agricultural Engineering - ATAE 2106”, 23-26
February, Opatija, Croatia.

Manera C., Minchilli M., Picuno P. 1990. L'abitazione rurale in Basilicata: analisi tipologica con metodologie fotogrammetriche [The rural house in Basilicata Region: typological analysis with photogrammetrical methodologies]. In: Proceedings of the 2nd Seminar of AIGR, 7-8 June, Città della Pieve, Italy.

Manera C., Picuno P., Tortora A. 2001. The utilisation of a geographical information system (GIS) for the valorisation of typical products from marginal areas. pp 223-233 in Proceedings of the International Congress Agribuilding 2001, 3-7 September, Campinas, Brazil.

Picuno P. 2012. Vernacular farm buildings in landscape planning: a typological analysis in a southern Italian region. J. Agricult. Engine. XLIII:130-7.

Picuno P. 2016. Use of traditional material in farm buildings for a sustainable rural environment. Int. J. Sustain. Built Environ. 5:451-60.

Picuno P., Stanovčić T., Moric I., Dimitrijević A., Sica C. 2015. The valorisation of vernacular farm buildings for an innovative rural tourism. pp 807-817 in Proceedings of the 43 International Symposium on Agricultural Engineering "Actual Tasks on Agricultural Engineering - ATAE 2105”, 24-27 February, Opatija, Croatia.

Simonicca A. 1997. Antropologia del turismo, strategie di ricerca e contesti etnografici. La Nuova Italia Scientifica, Roma, Italy, pp. 169-173.

Statuto D., Cillis G., Picuno P. 2015. Historical cartography and GIS tools for the analysis of land use and landscape changes. pp 441-450 in Proceedings of the 43rd Symposium on: "Actual Tasks on Agricultural Engineering - ATAE 2105, 24-27 February, Opatija, Croatia.

Statuto D., Cillis G., Picuno P. 2016. Analysis of the effect of agricultural land use change on rural environment and landscape through historical cartography and GIS tools. J. Agricult. Engine., XLVII:28-39.

Statuto D., Gatto A.G., Tortora A., Picuno P. 2014a. The use of a Geographical Information System to identify and valorise some pathways along the "HERCULIA WAY". In: Proceedings of International Conference: The European Pilgrimage Routes for promoting sustainable and quality tourism in rural areas, 4-6 December, Florence, Italy.

Statuto D., Tortora A., Picuno P. 2013a. Analysis of the evolution of landscape and land use in a GIS approach. In: Proceedings International Symposium ISAE 2013, 4-6 October, BelgradeZemun, Serbia, VI:25-33.

Statuto D., Tortora A., Picuno P. 2013b. A GIS approach for the quantification of forest and agricultural biomass in the Basilicata region. J. Agricult. Engine. XLIV:627-31.

Statuto D., Tortora A., Picuno, P. 2014b. Spatial modeling and image processing of historical maps for rural landscape planning. In: Proceedings of International Conference of Agricultural Engineering-EurAgEng 2014, 6-10 July, Zurich, Switzerland.

Tortora A., Statuto D., Picuno P. 2015. Rural landscape planning through spatial modelling and image processing of historical maps. Land Use Policy 46:71-82. 